\title{
Vigorous Groups? An Examination of Vigor at the Dimension Level and Its Relationship to Work Attitudes in Teams
}

\author{
Andrew J. Wefald \\ Kansas State University, \\ Manhattan, USA
}

\author{
Maura J. Mills \\ Hofstra University, \\ Hempstead, USA
}

\author{
Michael R. Smith \\ One Talent Plus Way, \\ Lincoln, USA
}

\author{
Ronald G. Downey \\ Kansas State University, \\ Manhattan, USA
}

\begin{abstract}
Vigor is an emerging job attitude that purports to measure employees' psychological and physical energy and cognitive involvement in their work. While vigor and leadership have been theoretically linked, to date no empirical study has investigated the purported relationship. The present research attempts to fill this gap. This study examined the constructs of leadership, vigor, job attitudes, and performance at the group level. Vigor and leadership were both linked to employee-centered measures while only vigor was linked to organizationally-relevant measures. Finally, vigor and perceptions of transformational leadership were positively related with one another.
\end{abstract}

Keywords: vigor, leadership, group, team, job attitudes, performance

\section{Introduction}

In organizations, the prospect of employees flourishing is of great interest and benefit to practitioners (Luthans, Avolio, Avey, \& Norman, 2007; Vance, 2006), and one way to explore how and when employee flourish is through the construct of vigor, as conceptualized by Shirom (2006). The purpose of the current study is to determine how the components of vigor relate to leadership, performance, and other important business-related attitudes, cognitions, and affects at the unit level. Through an analysis of the vigor components, this research also seeks to provide actionable recommendations that practitioners can use to facilitate vigor in its employees and, in turn, its subsequent outcomes and correlates.

Due in part to global competition and advances in technology, organizations are increasingly looking to groups and teams to deliver products and services. Various models of team effectiveness have been developed over the years. Many of those models include leadership, job attitudes (e.g., job satisfaction), and performance outcomes such as job performance and turnover — both at the individual level and group level (Salas, Stagl, Burke, \& Goodwin, 2007). The previous work suggests the types of variables chosen for this research are in line with previous frameworks of team effectiveness. The specific variables chosen incorporate a range of variables that highlight the importance and practical use of the group vigor concept. Previous research has shown that group work has a potential to increase both productivity and satisfaction (Campion, Medsker, \& Higgs, 1993).

Andrew J. Wefald, Ph.D., Assistant Professor, School of Leadership Studies, Kansas State University.

Maura J. Mills, Ph.D., Assistant Professor, Department of Psychology, Hofstra University.

Michael R. Smith, Ph.D., One Talent Plus Way.

Ronald G. Downey, Ph.D., Assistant Professor, Department of Psychological Sciences, Kansas State University. 
One area where the present study's exploration of group vigor may add to the theoretical framework on team effectiveness is through the concept of team or collective "potency". Potency refers to the belief by a group which can be effective. This idea stems from Bandura's (1982) self-efficacy concept. Bandura (1982) introduced the idea of self-efficacy which is the belief that one has the capability to perform a certain task and can achieve certain goals related to that task. Along with self-efficacy, Bandura also introduced the idea of collective efficacy which extends the idea of individual efficacy to a group ("a group's shared belief in its conjoint capabilities to organize and execute the courses of action required to produce given levels of attainments"; Bandura, 1997, p. 447). Research has supported a positive relationship between collective efficacy and organizational outcomes such as group problem-solving (Kline \& MacLeod, 1997), group learning (Edmondson, 1999), and performance in service (Gibson, 1999). Collective efficacy was found to be related to group performance with a meta-analysis (Gully, Incalcaterra, Joshi, \& Beaubien, 2002). Teams with more potency or "team spirit" may be more committed and may be more willing to work hard for the group (Campion, Medsker, \& Higgs, 1993; Campion, Papper, \& Medsker, 1996). Indeed, a recent meta-analysis by Stajkovic, Lee, and Nyberg (2009) suggested a positive and significant relationship ( $r=$ 0.35 ) between collective efficacy (potency) and team performance. This idea of potency is closely aligned with the concept of group vigor: An exploration of group vigor supports and adds to this theory by incorporating the concepts of physical strength, emotional energy, and cognitive liveliness with the concept of potency. In the authors' view, the degree to which a workgroup is vigorous (energetic, strong, cognitively lively) is likely to overlap substantially with the degree to which the group can be considered potent and demonstrate the associated collective efficacy beliefs, ultimately resulting in enhanced group performance. Further, Lester, Meglino, and Korsgaard (2002) suggested that teams with higher levels of group potency perform better than teams with lower levels. They also reported that little is known about how to increase group potency. Given the relationship between group potency and performance, the research on group vigor may be of particular utility.

As a relatively new construct, few researchers have explored vigor, as an independent affective component, as it relates to organizational behavior and performance. When vigor has been studied, the samples generally consisted of select populations including the mentally ill, students, or athletes (Shirom, 2006). Noting this limitation, Shirom (2003) developed a measure of workplace vigor entitled the SMVM (Shirom-Melamed Vigor Measure), designed to measure vigor as a positive work-related experience. Shirom (2003) defined vigor as, "a positive affective response to one's ongoing interactions with significant elements in one's job and work environment that comprises the interconnected feelings of physical strength, emotional energy, and cognitive liveliness" (p. 12). "Physical strength" represents the expression physical ability and feelings of physical vitality toward one's job. "Emotional energy" is embodied by interpersonal sympathy, warmth, and empathy for coworkers. "Cognitive liveliness" is characterized by using one's mental agility and awareness within a specific work environment. It is important to note that Shirom conceptualized vigor and its components as states. That is, each vigor component - and thus also vigor as an aggregate construct - is an effective response to one's work environment. Therefore, as the environment changes, so can the individual's physical, emotional, and cognitive responses to that environment change.

Shirom's (2003; 2006) use of physical, emotional, and cognitive energetic capacities was based upon Kahn's (1990) conceptualization of the similar construct of work engagement. First, Shirom (2006) suggested that although these three subcomponents are closely related, such that an expansion in one is often coupled with 
an increase in the others. However, they are individually possessed and can vary. Second, Shirom (2006) insisted that the three components "represent a coherent set that does not overlap with any other established behavioral science concept (e.g., resilience)... or any aspect of the self-concept (e.g., self-efficacy)... and clearly differentiates it from its likely consequences (e.g., engagement or job involvement)" (pp. 90-91). Finally, Shirom (2003) argued that proximal energetic resources represent a major precondition of all goal-oriented behavior and as such, are paramount to individual survival. Therefore, although vigor has been defined as a dimension of workplace engagement, according to Schaufeli, Salanova, Gonzalez-Roma, and Bakker (2002) and Schaufeli, Bakker, and Salanova (2006), vigorous engagement represents a more stable and persistent trait-like disposition whereas Shirom (2003) described vigorous affect as a more state-like and open to development via organizational intervention.

In addition to Kahn's (1990) influence on Shirom's (2003) development of the vigor construct, Hobfoll's (1989; 2001) COR (Conservation of Resources) theory also contributed to the theoretical construct development, as did Lazarus's (1991) cognitive-motivational theory. According to the COR theory, energy and effort in the workplace occur in response to favorable conditions that are likely to result in the gain of valued resources. In the context of COR theory, vigor represents a condition resource. Shirom (2003) characterized vigor as an affective reaction to significant ongoing interactions within the workplace. Accordingly, Shirom emphasized the importance of the context, and specifically, the work, the work environment, and workplace encounters as primary elements impacting the willingness of employees to express physical strength, emotional energy, and cognitive liveliness. As with all condition resources, the extent to which employees are willing to display vigorous affect in the workplace is contingent on the connection of these behaviors to the acquisition of additional resources (Hobfoll, 2001). Organizations that are structured such that the expression of vigorous affect and behavior is promoted and rewarded are likely to improve employee engagement, job satisfaction, turnover intentions, and job performance.

Although vigor as a construct is broken down into three components, it is rarely researched as multi-dimensional (Shirom, 2003; Shirom \& Shraga, 2009). These researchers have theoretically suggested a number of psychological, physiological, genetic, and incentive-based work-related characteristics that are likely to have a relationship with unidimensional vigor. Work-related attitudes and behaviors including job characteristics, multiple and/or conflicting roles, the use of teams and work groups, and the leadership style of organizational leaders were hypothesized to be significant antecedents of vigor. Although Shraga and Shirom (2009) showed that vigor as a unidimensional construct is meaningfully related to a number of job characteristics and attitudes, there is reason to believe that studying the relationship of relevant organizational constructs at the dimension level will also provide an important contribution to the field. Harter and Schmidt (2008) argued that the practical value of a measure, and presumably research in general, depend on the usefulness of the information provided. Research recommendations that are specific and prescriptive are more useful to managers to aid organizational decision-making than recommendations that are broad and descriptive. Studying vigor at the dimensional level and finding meaningful relationships between the physical strength, emotional energy, and cognitive liveliness components of vigor and outcome variables provides managers and leaders with actionable information to improve organizational effectiveness and aid in decision-making.

Empirical research replicating the three-factor structure of the SMVM (Shirom, 2003) by Shraga (2007) and Smith, Wefald, Downey, and Gopalan (2008) has supported the SMVM as a reliable and valid measure of 
workplace vigor (Shraga, 2007; Smith et al., 2008). In addition, the three factors were found to share positive and significant relationships with positive work-related attitudes including job satisfaction, self-reported performance, and service orientation. Collectively, these results support the SMVM as a reliable and valid multi-dimensional measure of workplace vigor.

Despite supportive findings at the individual level, Pugh and Dietz (2008) suggested that the practical utility of positive organizational behavior to practitioners and consultants is contingent on its ability to inform decision-making at the unit-level. Pugh and Dietz (2008) argued that the language and metrics used in organizational decision-making often occur at the unit-level of analysis, and as such, organizational interventions are often focused on improving unit-level characteristics and outcomes. Thus, in addition to evaluating the multidimensional vigor construct at the group-level, the current research also seeks to evaluate whether the relationships found at the individual level for job satisfaction and performance (Shragra, 2007; Smith et al., 2008) can be replicated at the group-level.

Fredrickson's (1998) broaden and build theory posits that positive emotions broaden people's thought-action repertoires such as flight or fight and this encourages people to discover novel lines of thought or action. For example, joy creates the desire to play and interest in something creates the desire to explore (Fredrickson \& Joiner, 2002). As people discover new ideas and actions, they build their physical, intellectual, social, and psychological resources. Positive emotions also broaden attention and cognition (which enable flexible and creative thinking) and predict broad-minded coping (e.g., thinking of new ways to solve problems) (Fredrickson \& Joiner, 2002). Along with the broaden and build theory, emotional contagion (Hatfield, Cacioppo, \& Rapson, 1993) is a process where one person can "catch" the positive emotions of another person. Over time a group can experience more or less vigor than other groups. And vigor could potentially broaden and build through a group and spread to other group members.

Although vigor is measured at the individual-level, similar research has aggregated individually-measured constructs such as job satisfaction, commitment, and job involvement to the group level. Most notably, Harter, Schmidt, and Hayes (2002) researched employee engagement, a construct very similar to vigor (Shirom, 2003), and found meaningful relationships between engagement and employee satisfaction, customer satisfaction, productivity, profit, turnover, and accidents by aggregating individual-level data to the group level. Logically, we can see how certain groups may possess higher or lower levels of physical strength, emotional energy, and cognitive liveliness. As outlined by Shirom (2006), vigor as an affective state is influenced by numerous organizational-based initiatives including supervisor transformational leadership style, participative decision-making, the organizational reward structure, social support, resource control, cohesiveness, and one's level of autonomy. Each of these characteristics is likely to differ over units and is, therefore, likely to influence the shared affective states experienced within each group differently (George, 1990; George \& James, 1993; Pugh \& Dietz, 2008). In the current study, the aggregation of the variables to the unit-level is useful in providing insight into how vigorous affect influences behaviors within work groups and facilitates organizational improvement.

Despite the strong theoretical arguments supporting the aggregation of individual-level data to the group level, it is also important to verify the aggregation empirically. Pugh and Dietz (2008) noted that group members within a unit are likely to have similarities in personality and affective states, and therefore measuring employee engagement at the individual level of analysis and aggregating those scores to the unit level is appropriate if within-unit agreement can be first established. Procedures by James, Demaree, and Wolf (1984) 
will be used to evaluate the level of within agreement within each business unit and the extent to which the aggregation of the individual scores to the group level can be supported empirically.

While vigor and its components are the main foci of the present study, other constructs are also included and thus are deserving of at least brief mention and explanation. In particular, the other organizational variables have been theoretically or empirically linked to vigor at the individual level of analysis. These constructs include transformational leadership, workplace engagement, job and life satisfaction, affective commitment, organizational support, job involvement, intentions to leave, and performance. Literatures linking each of these outcomes to vigor will be briefly reviewed.

In a 2006 article designed to facilitate research on the identification of the antecedents and consequences of vigor, Shirom (2006) hypothesized a number of "expected" business-related antecedents, "probable" moderator genetic and physiological variables, and "possible" outcomes related to vigor. The antecedents were structured under four categories: organizational resources, group-level resources, job-related resources, and individual resources. Organizational resources included participation in decision-making, extrinsic rewards, and intrinsic rewards and practices. Group-level resources included transformational leadership behaviors, social support, and cohesiveness. Job-related resources included personal control over resources, positional power, and autonomy, and individual resources included to personal charisma, expertise, and power. Shirom (2006) theoretically suggested outcomes of vigor to include job satisfaction, life satisfaction, job performance, physical and mental wellness, and organizational effectiveness.

While the majority of past research has investigated the vigor construct as unidimensional, Shirom (2006) suggested that "It is possible for each of (vigor's) components to be differentially associated with the antecedents and consequences" (p. 91). Consistent with this idea, the present study considers each of the vigor components individually. Considering that the present study's exploration of the vigor components at the unit-level lacks precedence and therefore lacks sufficient theoretical or empirical reasoning to propose differential effect sizes for any of the three vigor components, equivalent hypotheses will be evaluated for each of the components as they relate to the study variables.

\section{Hypotheses}

Hypothesis 1: The physical energy component of vigor will be significantly and positively related to engagement, job satisfaction, life satisfaction, organizational support, and group performance. This relationship will be negative for intent to turnover.

Hypothesis 2: The cognitive liveliness component of vigor will be significantly and positively related to engagement, job satisfaction, life satisfaction, organizational support, and group performance. This relationship will be negative for intent to turnover.

Hypothesis 3: The emotional energy component of vigor will be significantly and positively related to engagement, job satisfaction, life satisfaction, organizational support, and group performance. This relationship will be negative for intent to turnover.

\section{Method}

\section{Participants}

Participants were 382 employees and managers at a mid-sized financial institution in the United States. Participants were identified by the management of the organization from two lines of business. A 
total of 671 participants were identified by the organization and those participants were sent surveys electronically. Four hundred and fifty one employees accessed the survey. However, 69 people did not complete the survey and were therefore eliminated from the analysis for a total sample size of 382 and a $57 \%$ response rate. Participating employees worked in 34 different groups, and were thus analyzed as such in order to account for potential group differences. Mean group size was 10.67 employees $(S D=4.42$; Min. $=5$, Max. $=20$ ).

In addition to the major study variables mentioned earlier, for trending purposes, the survey also included demographic items suggested by the organization in order to remain consistent with other surveys the organization administers. Participants were $51.4 \%$ male and the ages of the participants were as follows: under 25 (1.9\%), 25-35 (22.3\%), 36-45 (28.3\%), 46-55 (33.8\%), and over 55 (12.7\%). The education levels of the participants were as follows; high school/GED (General Education Development) (6.2\%), some college (32.9\%), 4-year-college BA/BS (Bachelor of Arts/Bachelor of Science) (44.5\%), Master's (10.8\%), and professional or doctoral degree (5.7\%). Organizational tenure of participants was as follows: less than 1 year $(7.7 \%), 1-3$ years $(17.9 \%), 4-10$ years $(36.1 \%), 11-19$ years $(24 \%)$, and 20 years or more $(14.3 \%)$. Finally, $22.2 \%$ of participants self-identified as managers.

\section{Measures}

Vigor. Vigor was measured using the SMVM by Shirom (2003). The SMVM consists of 12 items designed to measure the physical strength, cognitive liveliness, and emotional energy dimensions of vigor. Shirom (2003) reported reliabilities of 0.95 for physical strength, 0.72 for cognitive liveliness, and 0.88 for emotional energy. Similarly, Smith et al. (2008) reported alpha coefficients of $0.88,0.76$, and 0.91 , respectively. Items were measured on a 7 -point Likert scale $(1=$ "Never or almost never" to $7=$ "Always or almost always").

Transformational leadership. Transformational leadership was measured using the GTL (global transformational leadership) scale (Carless, Wearing, \& Mann, 2000). Carless et al. (2000) have found the GTL to have good reliability ( $\alpha=0.93$ ), and also to have strong convergent validity with other, established measures of transformational leadership such as the MLQ (multifactor leadership questionnaire) and the LPI (leadership practices inventory). The correlations between the GTL and the MLQ and LPI ranged from 0.76 to 0.88 (Carless et al., 2000). The 7-item scale was measured using a 5-point Likert scale ( $1=$ "Strongly disagree" to 5 $=$ "Strongly agree").

Engagement. Engagement was measured using the 9-item version of the UWES (Utrecht work engagement scale) from Schaufeli, Salanova, Gonzalez-Roma, and Bakker (2002) called the UWES-9. This abridged version of the scale has been shown to have acceptable alpha reliabilities ranging from 0.77 to 0.92 (Schaufeli et al., 2006), and has been found by recent research to be a potentially better alternative to the original 17-item version of the scale (Mills, Culbertson, \& Fullagar, 2012). Items were measured using a 7-point Likert scale ( 1 = "Never" to 7 = "Always, everyday").

Job satisfaction. Job satisfaction was measured using Brayfield and Rothe's (1951) scale which consisted of five items measured on a 5-point Likert scale ( 1 = "Strongly disagree" to $5=$ "Strongly agree"). Brayfield and Rothe (1951) reported an odd/even product moment reliability of 0.77 .

Life satisfaction. Life satisfaction was measured using Diener, Emmons, Larsen, and Griffin's (1985) scale which consisted of five items measured on a 5-point Likert scale $(1=$ "Strongly disagree" to $5=$ 
"Strongly agree"). Diener and colleagues (1985) reported a coefficient alpha of 0.87 for this scale and a two-month test-retest correlation of 0.82 .

Affective commitment. Affective commitment was measured using a shortened version of affective commitment items from Allen and Meyer's (1990) organizational commitment scale. The original scale had eight items for the affective commitment subscale, while the shortened version used in this study consisted of only the four items with the highest factor loadings from the 1990 study. The reported Cronbach alpha coefficients for the longer form of the affective commitment subscale was 0.86 (Allen \& Meyer, 1990). Items were measured using a 5-point Likert scale ( 1 = "Strongly disagree" to 5 = "Strongly agree").

Intent to turnover. Intent to leave was measured using a combination of Keller's (1984) intent to leave scale and Blau and Holliday's (2006) scale. Keller's (1984) intent to leave scale had limited reliability ( $\alpha=$ 0.67), so in an effort to improve reliability it was combined with Blau and Holliday's (2006) intent to leave scale $(\alpha=0.91)$. Each scale was comprised of three items for a total of six items $(\alpha=0.92)$. Items were measured on a 5-point Likert scale ( 1 = "Strongly disagree" to 5 = "Strongly agree").

Perceived organizational support. Perceived organizational support was measured using items from Eisenberger, Huntington, Hutchinson, and Sowa's (1986) scale. The original scale reported a Cronbach's alpha reliability coefficient of 0.97 . This scale had eight items measured on a 5-point Likert scale $(1=$ "Strongly disagree" to 5 = "Strongly agree").

Job involvement. Job involvement was measured using Kanungo's (1982) scale. The scale consisted of 10 items measured on a 5-point Likert scale ( 1 = "Strongly disagree" to 5 = "Strongly agree"). Kanungo (1982) reported the reliability of this scale to be 0.85 .

Performance. Performance rankings were provided by a top executive at the organization. This individual ranked all groups for which he was responsible based on internal criteria such as objective financial performance and overall effectiveness. The researchers received the rankings from the organization and the executive; however, we were not given the specific criteria upon which the rankings were based.

\section{Procedure}

The management of the organization sent out notification and explanation of the survey prior to administration. In addition to the aforementioned scales, participants were asked questions regarding their direct supervisor, line of business, and department. This was done in order to ensure that each participant was subsumed within the correct group during data aggregation and analysis.

The organization administers its own internal annual employee well-being survey consisting of 20 items ("Q20" survey). The organization provided the researchers with the results of the Q20 for the year this data was collected (2007) and also with data from 60 separate groups of participants that completed the survey. Thirty-four groups could be linked from the Q20 to the survey administered by the researchers, and these groups comprise the group sample size for this study ( $N=34$ groups).

A top executive at the organization ranked all groups based on internal criteria such as objective financial performance and overall effectiveness, although the organization would not furnish these criteria to the researchers. Thus, the only performance data available to the researchers were the rankings. Some groups remained unranked: (1) if they failed to meet a minimum group size of five (due to confidentiality issues); and/or (2) if the group leader could not be identified. Therefore, of the original 34 groups, 18 were ranked by the executive, with " 1 " being the most effective group and " 18 " being the least effective group. 


\section{Analysis}

The data were first examined using visual scans of data plots, means, SDs (standard deviations), skew, kurtosis, and scale minimums and maximums. For the structural model analyses the data were imputed using SPSS's (Statistical Product and Service Solutions) linear trend at point method. The linear trend at point data imputation method replaces missing values with the linear trend for that point using regression and missing values are replaced with predicted values.

The means reported in Table 2 were calculated from the individual scores on the measures. A team's score was calculated by summing the scores of the individuals in that team. Those team scores were then divided by the number of items in each scale.

It should be noted that, while HLM (hierarchical linear modeling) analyses are often preferable for group-level data, such analytic procedures were not employed in the present analysis for a variety of reasons. First, HLM is a large-sample technique (Kreft, 1996) that requires a minimum of 30 participants in each of 30 groups in order to yield sufficient power (Bassiri, 1988; van der Leeden \& Busing, 1994), whereas the present sample has an average of 12 participants in each of 34 groups and, where performance is used as a criterion, has only 18 groups. HLM also requires that the outcome variable be measured at the lowest level of analysis (Hofmann et al., 2000). As required by the organization, the present design measures the outcome at the group level of analysis, rather than at the individual level. This resulted in an outcome variable that yielded performance rankings for 18 of the 34 groups, and no performance data on specific individuals. Further, HLM is most appropriate for examinations of whether groups impact individuals, not whether individual leadership style (as is of interest in the present article) impacts upon individual characteristics (e.g., employee levels of engagement). Therefore, regression analytic techniques were more appropriate than HLM in the present study.

\section{Results}

In order to empirically determine that vigor and the other constructs were indeed group-level constructs, as opposed to the simple aggregation of individual-level scores, we conducted WABA (within and between groups analysis) analysis and calculated the average within-group interrater reliability (rwg) for the study variables as denoted by James, Demaree, and Wolf (1984). Groups with five or fewer respondents were eliminated leaving a final $N$ of 34 groups. In addition, groups with rwg values less than 0.60 were considered unreliable and assigned a value of 0.00 . The average within-group interrater reliability (rwg), range of rwg, and number of unreliable groups (i.e., group with $\mathrm{rwg} \leq 0.00$ ) for each study variables were as follows: physical strength vigor ( $\mathrm{rwg}=0.91$; rwg range $=0.80-0.98 ; 0$ unreliable groups), cognitive liveliness vigor ( $\mathrm{rwg}=0.84$; rwg range $0.60-0.96 ; 1$ unreliable groups), emotional energy vigor ( $\mathrm{rwg}=0.87$; rwg range $0.71-0.97 ; 1$ unreliable groups), overall vigor ( $\mathrm{rwg}=0.96$; rwg range $=0.91-0.98 ; 0$ unreliable groups), transformational leadership ( rwg $=0.80$; rwg range $=0.65-0.98 ; 3$ unreliable group), engagement ( $\mathrm{rwg}=0.91 ; \mathrm{rwg}$ range $=$ $0.74-0.97 ; 0$ unreliable groups), job satisfaction ( $\mathrm{rwg}=0.85 ; \mathrm{rwg}$ range $=0.67-0.96 ; 1$ unreliable groups), intent to leave ( $\mathrm{rwg}=0.79$; rwg range $=0.62-0.99 ; 5$ unreliable groups), affective commitment ( $\mathrm{rwg}=0.75$; rwg range $=0.67-0.91 ; 4$ unreliable group), life satisfaction ( $\mathrm{rwg}=0.84 ; \mathrm{rwg}$ range $=0.67-0.97 ; 1$ unreliable group), organizational support ( $\mathrm{rwg}=0.90 ; \mathrm{rwg}$ range $=0.78-0.99 ; 0$ unreliable groups), and job involvement (rwg $=0.91 ;$ rwg range $=0.82-0.96 ; 0$ unreliable groups). Overall, these results indicate that the full-time and part-time workers within an organization are reporting consistent levels of positive attitudes and behaviors. 
Therefore, the study variables can be meaningfully evaluated at the group level.

Before beginning analyses of group variables, it is important to verify that measurable group differences exist. The group differences are reported in Table 1. Means, $S D$ s, and intercorrelations for all study variables are reported in Table 2. Hypothesis 1 suggested that physical strength would be significantly related to the study variables under consideration. Correlation results yielded a significant and moderate relationship for engagement $\left(r_{(30)}=0.61, p<0.01\right)$, job satisfaction $\left(r_{(30)}=0.51, p<0.01\right)$, life satisfaction $\left(r_{(30)}=0.56, p<\right.$ $0.01)$, organizational support $\left(r_{(30)}=0.41, p<0.01\right)$, and group performance $\left(r_{(13)}=-0.66, p<0.01\right)$. Thus, Hypothesis 1 was partially supported.

Table 1

Univariate ANOVA (Analysis of Variance) for Vigor and Dimensions

\begin{tabular}{llllll}
\hline & $S S$ & $d f$ & $M S$ & $F$ & $p$ \\
\hline 1. Vigor & $7,917.72$ & 50 & 158.35 & 1.70 & 0.004 \\
2. Cognitive liveliness & $1,207.44$ & 50 & 24.15 & 1.79 & 0.002 \\
3. Physical strength & $1,107.44$ & 50 & 22.15 & 1.41 & 0.043 \\
4. Emotional energy & $1,209.58$ & 50 & 24.19 & 1.39 & 0.049 \\
\hline
\end{tabular}

Notes. $S S=$ Sum of squares; $d f=$ Degrees of freedom; $M S=$ Mean square.

Hypothesis 2 suggested that cognitive liveliness would be significantly related to the study variables under consideration. Correlation results yielded only one significant correlation with life satisfaction $\left(r_{(30)}=0.48, p<\right.$ 0.01 ). Thus, there was minimal support for hypothesis 2 .

Hypothesis 3 proposed that emotional energy would be significantly related to the study variables under consideration. Correlations yielded a significant and positive moderate result for transformational leadership $\left.r_{(30)}=0.37, p<0.05\right)$ only. Thus, hypothesis 3 also received minimal support.

Table 2

Means, SDs, Intercorrelations, and Reliability Coefficients for All Study Variables $(N=34)$

\begin{tabular}{|c|c|c|c|c|c|c|c|c|c|c|c|c|c|c|}
\hline & $M$ & $S D$ & 1 & 2 & 3 & 4 & 5 & 6 & 7 & 8 & 9 & 10 & 11 & 12 \\
\hline 1. Vigor physical strength & 3.72 & 1.45 & 0.94 & & & & & & & & & & & \\
\hline $\begin{array}{l}\text { 2. Vigor cognitive } \\
\text { liveliness }\end{array}$ & 6.66 & 1.73 & $0.69^{* *}$ & 0.81 & & & & & & & & & & \\
\hline 3. Vigor emotional energy & 5.51 & 1.63 & $0.51^{* *}$ & 0.29 & 0.91 & & & & & & & & & \\
\hline $\begin{array}{l}\text { 4. Transformational } \\
\text { leadership }\end{array}$ & 3.70 & 3.08 & 0.28 & 0.23 & $0.37^{*}$ & 0.96 & & & & & & & & \\
\hline 5. Engagement total & 5.13 & 3.63 & $0.61^{* *}$ & 0.33 & 0.24 & 0.34 & 0.92 & & & & & & & \\
\hline 6. Job satisfaction & 3.82 & 1.39 & $0.51^{* *}$ & 0.27 & 0.15 & 0.32 & $0.76^{* *}$ & 0.77 & & & & & & \\
\hline 7. Intent to leave & 1.91 & 1.94 & -0.29 & -0.13 & -0.07 & -0.20 & $-0.53^{* *}$ & $-0.69^{* *}$ & 0.93 & & & & & \\
\hline 8. Affective commitment & 3.15 & 1.50 & 0.17 & -0.05 & -0.04 & 0.25 & $0.57^{* *}$ & $0.69^{* *}$ & $-0.70^{* *}$ & 0.91 & & & & \\
\hline 9. Life satisfaction & 3.51 & 1.56 & $0.56^{* *}$ & $0.48^{* *}$ & 0.14 & $0.39^{*}$ & $0.68^{* *}$ & $0.60^{* *}$ & -0.23 & 0.17 & 0.91 & & & \\
\hline 10. Organizational support & 3.44 & 2.89 & $0.41^{*}$ & 0.26 & 0.10 & $0.72^{* *}$ & $0.52^{* *}$ & $0.6^{1 * *}$ & $-0.60^{* *}$ & $0.64^{* *}$ & $0.40^{*}$ & 0.95 & & \\
\hline 11. Job involvement & 2.66 & 3.22 & 0.25 & 0.15 & -0.21 & 0.02 & $0.43^{*}$ & 0.32 & -0.22 & 0.33 & 0.33 & 0.25 & 0.91 & \\
\hline 12. Group performance & 8.54 & --- & $-0.66^{* *}$ & -0.26 & -0.05 & $-0.58^{* *}$ & $-0.69^{* *}$ & $-0.74^{* *}$ & 0.51 & $-0.79^{* *}$ & -0.48 & $-0.76^{* *}$ & & -0.33 \\
\hline
\end{tabular}

Notes. " Correlation is significant at the $p<0.01$ level (2-tailed); "Correlation is significant at the $p<0.05$ level (2-tailed); All variables $(N=34)$ except group performance $(N=18)$; Reliability coefficients are presented in bold in the diagonal; The $S D$ is not reported for group performance due to the measurement (ranked) of this variable, which makes the $S D$ meaningless.

\section{Discussion}

Both research and practice are increasingly attending to positive organizational behavioral constructs. Despite these efforts, however, few organizations or researchers have evaluated the impact of vigor at the 
group-level. This is an area of crucial importance, given the increasing popularity of groups and teams within organizations both within the United States and abroad (e.g., Salas et al., 2009), and the need for organizations to find cost-effective methods to improve employee morale and performance.

The present study serves to link vigor-in particular the physical strength component - to critical employee and organizational outcomes at the group level. As theorized by Shirom (2006), the components of vigor differentially related to the variables in the present study. Physical strength yielded the strongest relationships and was found to be empirically related to workplace engagement, job and life satisfaction, organizational support, and group performance. The results for cognitive liveliness and emotional energy were not as promising as the components only related to life satisfaction and transformational leadership, respectively. For a number of other correlates, the results provide hope that these relationships may exist with a larger sample size. In particular, although transformational leadership was not significant for the physical strength and cognitive liveliness components, the direction of the relationship was positive. Similarly, cognitive liveliness showed promising results for work engagement, job satisfaction, organizational support, and turnover intentions. The results for emotional energy suggest that emotional energy does not play as a critical role in facilitating group-related affect as physical energy does.

As stated previously, many models of team effectiveness have been developed over the years. These models have included leadership, job attitudes, and performance outcomes such as job performance and turnover. This research extends the theory of team potency to group vigor. Team potency stems from Bandura's collective (and self) efficacy concept and social cognitive theory. The idea of potency is closely related to the concept of group vigor. Theoretically, a group's collective efficacy (potency) should be related to the amount of physical, emotional, and cognitive vigor a group possesses. With heightened vigor in a group, the group should experience higher levels of potency - feeling and believing they can successfully complete tasks. The extension of team potency to group vigor is supported by incorporating the concepts of physical strength, emotional energy, and cognitive liveliness with the concept of potency. Improving the level of physical energy within the workforce is likely to lead to improved group-related affect. Physical energy holds great importance for organizations because of its relationship with alternative workplace energies. Wood, Mangello, and Jewell (1990) found that physical energy was significantly positively correlated with mental energy, positive effect, and vigor. Similarly, Smith et al. (2008) found vigor to be related to engagement, coping, perceptions of quality of life, and job satisfaction. In addition, physical energy shared a negative relationship with fatigue. In a recent study reviewing vigor, its antecedents, and its correlates, Shirom (in press) argued that physical health is likely to be positively associated with increased vigor and job performance. Similarly, Shirom, Toker, Jacobson, and Balicer (2010) also supported a potential connection between vigor and physical activity in concluding that "Vigor may influence physical health by encouraging exercising to enhance physical fitness" (p. 728). Yet, encouraging physical activity in employees can be a difficult task. Dunn, Anderson, and Jakicic (1998) emphasized that the implementation of practices promoting the adoption and maintenance of a physically active lifestyle must balance a number of key issues. Thus, the implementation of any effort to promote physical vigor in the workplace must take into account the dynamics of the population, the associated costs, and the extent to which the program can be instituted on a larger population.

In their meta-analysis, Kahn et al. (2002) identified the types of interventions that would be effective in increasing participation in physical activity within the workplace. They found that when physical activity interventions were backed by a holistic organizational effort, including education, social support, 
individually-focused health behavior change programs, and access to physical activity, physical activity increased. Such organizational involvement promotes cohesion, collective self-efficacy, and social capital that help to strengthen persistence in physical activity. Kahn et al. (2002) suggested that individually-focused interventions in particular are likely to have strong results and facilitate improvements in physical activity and health. Similar arguments were offered for efforts enacted to increase employee access to environments where physical activity can be readily accessed. Developing partnerships with agencies to reduce cost-related barriers, or allowing time for workers to use on-site facilities was found to be effective in increasing physical activity. Similarly, ensuring that health counseling and education are available and setting up incentive-based programs that reward healthy behaviors may be effective ways to induce physical activity, and thereby positive affect related to physical vigor and self-esteem (Dunn et al., 1998; Kahn et al., 2002).

\section{Limitations and Future Directions}

Nevertheless, as with all research, the present study also had its limitations. Most notably among these is arguably the study's survey methodology and cross-sectional design. However, various researchers (Spector, 2006; Goffin \& Gellatly, 2001) have indicated that the criticisms commonly levied against mono-method, self-report studies are not as warranted as had previously been presumed. In particular, in studies in which both are available, self-report data tend to be highly correlated with other-report data to the degree that one alone would yield sufficient information. In order to provide initial evidence that common method variance was not of substantial detriment in our study, we conducted a Harman's single-factor test, whereby an exploratory factor analysis is conducted and emergence of either one factor or one predominant factor that accounts for a majority of the variance is indicative of potential common method variance problems. In order to ensure this was not the case, we ran a Harman's single-factor test, with results indicating that three factors emerged and therefore serving as a rudimentary indication that common method variance was unlikely to be present in these data (A principal components analysis was performed with varimax rotation and Kaiser normalization. The cumulative percent of variance explained by the three factors was $74.73 \%$. Each factor had $31.61 \%, 30.68 \%$, and $12.43 \%$ respectively) (see Table 3 ).

Table 3

Harman's Single-Factor Test Results Rotated Component Matrix

\begin{tabular}{llcr}
\hline & \multicolumn{2}{c}{ Component } \\
\cline { 2 - 4 } & 1 & 2 & 3 \\
\hline Perceived organizational support & 0.843 & 0.195 & 0.195 \\
Job involvement & 0.313 & 0.249 & 0.697 \\
Vigor total & 0.103 & 0.928 & 0.300 \\
Vigor physical strength & 0.246 & 0.887 & 0.049 \\
Vigor cognitive liveliness & -0.001 & 0.846 & 0.009 \\
Vigor emotional energy & 0.028 & 0.536 & 0.663 \\
Engagement total & 0.662 & 0.534 & -0.218 \\
Job satisfaction & 0.795 & 0.370 & -0.161 \\
Life satisfaction & 0.361 & 0.661 & -0.236 \\
Transformational leadership & 0.527 & 0.247 & 0.537 \\
Affective commitment & 0.887 & -0.088 & -0.129 \\
Intent to leave & -0.805 & -0.072 & 0.052 \\
\hline
\end{tabular}

Furthermore, organizational constraints only allowed for performance assessment of 18 of the 34 groups, 
all of which were in the same line of business. In addition, group performance was evaluated by an executive within said line of business who ranked each of the 13 groups. Therefore, performance was assessed by a forced-ranking system that: (1) was subject to the subjective interpretation of performance by the ranking executive; and (2) eliminated the possibility for groups performing at approximately equal levels to be given the same performance rating, since one necessarily had to be ranked above the other.

Future research would do well to replicate the present study on a larger sample. While the number of individual employees in the present study was substantial, once aggregated into their respective groups for analysis, the sample size (which became the number of groups) was considerably diminished (to $N=34$ ). As mentioned previously, this limited sample size prevented our ability to analyze the data using hierarchical linear modeling, and perhaps the generalizability of our results into other domains and/or populations. Future research would do well to replicate this study within a large organization that has widespread utilization of workgroups, thereby increasing the sample size once participants are aggregated into teams. Similarly, it would also be worthwhile to replicate the research on an international level. That is, with the increased popularity of global and virtual groups and teams, it would be interesting for future research to contrast such groups with more traditional co-located groups such as those studied herein.

\section{Conclusions}

Despite these limitations, finding similar significant relationships for the vigor components at the group level, specifically physical strength, as those theoretically hypothesized by Shirom (2006) and found by Smith et al. (2008) holds promise for understanding the positive contributions of vigor and engagement to both employee-related and organizational-related outcomes. The results of the current study contend that whether the goal is to improve the productivity and performance of a workgroup, positive work-related constructs (e.g., engagement), or satisfaction within one's work life physical energy plays an important role. Introducing interventions and incentives to promote worker persistence in achievement in physical engaging behaviors may be one method though which organizationally-relevant group goals and outcomes can be achieved.

Although the results reported herein are preliminary, and additional research is needed to develop a more complete understanding of vigor and its unique contribution to organizational effectiveness (Macey \& Schneider, 2008), the current research provides a foundation upon which subsequent research can build. Specifically, it provides an initial examination of the relationship between vigor and a number of relevant employee-centered and organization-centered variables that are of practical significance. Moreover, the present research contributes to and expands upon the nomological network of vigor and positions it as a construct that provides a unique contribution to understanding and improving organizational effectiveness. Finally, the results suggest the ability to aggregate the measure used in this study into group level variables.

\section{References}

Allen, N. J., \& Meyer, J. P. (1990). The measurement and antecedents of affective, continuance and normative commitment to the organization. Journal of Occupational Psychology, 63, 1-18. doi:10.1006/jvbe.2001.1842

Bandura, A. (1982). Self-efficacy mechanisms in human agency. American Psychologist, 37, 122-147.

Bandura, A. (1997). Self-efficacy: The exercise of control. New York: Freeman \& Company.

Bassiri, D. (1988). Large and small sample properties of maximum likelihood estimates for the hierarchical linear model (Unpublished dissertation, Michigan State University, East Lansing). 
Blau, G., \& Holliday, E. B. (2006). Testing the discriminant validity of a four-dimensional occupational commitment measure. Journal of Occupational and Organizational Psychology, 7, 691-704. doi:10.1348/096317905X69591

Brayfield, A. H., \& Rothe, H. F. (1951). An index of job satisfaction. Journal of Applied Psychology, 35, $307-311$. doi:10.1037/h0055617

Campion, M. A., Medsker, G. J., \& Higgs, C. A. (1993). Relations between work group characteristics and effectiveness: Implications for designing effective work groups. Personnel Psychology, 46(4), 823-850.

Campion, M. A., Papper, E. M., \& Medsker, G. J. (1996). Relations between work group characteristics and effectiveness: A replication and extension. Personnel Psychology, 49(2), 429-452.

Carless, S. A., Wearing, A. J., \& Mann, L. (2000). A short measure of transformational leadership. Journal of Business and Psychology, 14, 389-405.

Diener, E., Emmons, R. A., Larsen, R. J., \& Griffin, S. (1985). The satisfaction with life scale. Journal of Personality Assessment, 49, 71-75. doi:10.1207/s15327752jpa4901_13

Dunn, A. L., Andersen, R. E., \& Jakicic, J. M. (1998). Lifestyle physical activity interventions: History, short- and long-term effects, and recommendations. American Journal of Preventive Medicine, 15, 398-412. doi:10.1016/S0749-3797(98)00084-1

Edmondson, A. (1999). Psychological safety and learning behavior in work teams. Administrative Science Quarterly, 44, $350-383$.

Eisenberger, R., Huntington, R., Hutchinson, S., and Sowa, D. (1986). Perceived organizational support. Journal of Applied Psychology, 71, 500-507. doi:10.1037//0021-9010.71.3.500

Fredrickson, B. L. (1998). What good are positive emotions? Review of General Psychology, 2(3), 300-319.

Fredrickson, B. L., and Joiner, T. (2002). Positive emotions trigger upward spirals toward emotional well-being. Psychological Science, 13(2), 172-175.

George, J. M. (1990). Personality, affect, and behavior in groups. Journal of Applied Psychology, 75, 107-116. doi:10.1037//0021-9010.75.2.107

George, J. M., \& James, L. R. (1993). Personality, affect, and behavior in groups revisited: Comment on aggregation, levels of analysis, and a recent application of within and between analyses. Journal of Applied Psychology, 78, 798-804. doi:10.1037//0021-9010.78.5.798

Gibson, C. B. (1999). Do they do what they believe they can? Group efficacy and group effectiveness across tasks and cultures. Academy of Management Journal, 42, 138-152.

Goffin, R. D., \& Gellatly, I. R. (2001). A multi-rater assessment of organizational commitment: Are self-report measures biased? Journal of Organizational Behavior, 22, 437-451. doi:10.1002/job.94

Gully, S. M., Incalcaterra, K. A., Joshi, A., \& Beaubien, J. M. (2002). A meta-analysis of team-efficacy, potency, and performance: Interdependence and level of analysis as moderators of observed relationships. Journal of Applied Psychology, 87, 819-832.

Harter, J. K., \& Schmidt, F. L. (2008). Conceptual versus empirical distinctions among constructs: Implications for discriminant validity. Industrial and Organizational Psychology, 1, 37-40.

Harter, J. K., Schmidt, F. L., \& Hayes, T. L. (2002). Business-unit-level relationship between employee satisfaction, employee engagement, and business outcomes: A meta-analysis. Journal of Applied Psychology, 87, 268-279. doi:10.1037//0021-9010.87.2.268

Hatfield, E., Cacioppo, J. T., \& Rapson, R. L. (1993). Emotional contagion. Current Directions in Psychological Science, 2(3), 96-99. doi:10.1111/1467-8721.ep10770953

Hobfoll, S. E. (1989). Conservation of resources: A new attempt at conceptualizing stress. American Psychologist, 44, 513-524. doi:10.1037//0003-066X.44.3.513. 2001

Hobfoll, S. E. (2001). The influence of culture, community, and the nested-self in the stress process: Advancing conservation of resources theory. Applied Psychology: An International Review, 50, 337-370. doi:10.1111/1464-0597.00062

Hofmann, D., Griffin, M., \& Gavin, M. (2000). The application of hierarchical linear modeling to organizational research. In K. Klein, \& S. Kozlowski (Eds.), Multi-level theory, research, and methods in organizations. San Francisco, C. A.: Jossey-Bass.

James, L. R., Demaree, R. G., \& Wolf, G. (1984). Estimating within-group interrater reliability with and without response bias. Journal of Applied Psychology, 69, 85-98. doi:10.1037/0021-9010.69.1.85

Kahn, E. B., Ramsey, L. T., Brownson, R. C., Heath, G. W., Howze, E. H., Powell, K. E., \& Corso, P. (2002). The effectiveness of interventions to increase physical activity: A systematic review. American Journal of Preventative Medicine, 22, 73-107. 
Kahn, W. A. (1990). Psychological conditions of personal engagement and disengagement at work. Academy of Management Journal, 33, 692-724. doi:10.2307/256287

Kanungo, R. N. (1982). Measurement of job and work involvement. Journal of Applied Psychology, 67, $341-349$. doi:10.1037//0021-9010.67.3.341

Keller, R. T. (1984). The role of performance and absenteeism in the prediction of turnover. Academy of Management Journal, 27, 176-183. doi: $10.2307 / 255965$

Kline, T. J. B., \& MacLeod, M. (1997). Predicting organizational team performance. Organizational Development Journal, 15, 77-84.

Kreft, I. G. G. (1996). Are multilevel techniques necessary? An overview, including simulation studies (Unpublished manuscript. California State University, Los Angeles).

Lazarus, R. S. (1991). Progress on a cognitive-motivational-relational theory of emotion. American Psychologist, 46, 819-834. doi:10.1037//0003-066X.46.8.819

Lester, S. W., Meglino, B. M., \& Korsgaard, M. A. (2002). The antecedents and consequences of group potency: A longitudinal investigation of newly formed work groups. Academy of Management Journal, 45(2), 352-368. doi:10.2307/3069351

Luthans, F., Avolio, B. J., Avey, J. B., \& Norman, S. M. (2007). Positive psychological capital: Measurement and relationship with performance and satisfaction. Personnel Psychology, 60, 541-572. doi:10.1111/j.1744-6570.2007.00083.x

Macey, W. H., \& Schneider, B. (2008). The meaning of employee engagement. Industrial and Organizational Psychology: Perspectives on Science and Practice, 1, 3-30. doi:10.1111/j.1754-9434.2007.0002.x

Mills, M. J., Culbertson, S. S., \& Fullagar, C. J. (2012). Conceptualizing and measuring engagement: An analysis of the Utrecht work engagement scale. Journal of Happiness Studies, 13, 519-545.

Pugh, S. D., \& Dietz, J. (2008). Employee engagement at the organizational level of analysis. Industrial and Organizational Psychology, 1, 44-47. doi:10.1111/j.1754-9434.2007.00006.x

Salas, E., Goodwin, G. F., \& Burke, C. S. (2009). Team effectiveness in complex organizations: Cross-disciplinary perspectives and approaches. New York, N. Y.: Taylor \& Francis Group.

Salas, E., Stagl, K. C., Burke, C. S., \& Goodwin, G. F. (2007). Fostering team effectiveness in organizations: Toward an integrative theoretical framework. In Modeling complex systems: Volume 52 of the Nebraska Symposium on Motivation. Lincoln, N. E.: University of Nebraska Press.

Schaufeli, W. B., Bakker, A. B., \& Salanova, M. (2006). The measurement of work engagement with a short questionnaire: A cross-national study. Educational and Psychological Measurement, 66, 701-716.

Schaufeli, W. B., Salanova, M., Gonzalez-Roma, V., \& Bakker, A. B. (2002). The measurement of engagement and burnout: A two sample confirmatory factor analytic approach. Journal of Happiness Studies, 3, 71-92.

Shirom, A. (in press). Vigor as a positive affect at work: Conceptualizing vigor, its relations with related constructs, and its antecedents and consequences. Review of General Psychology.

Shirom, A. (2003). Feeling vigorous at work? The construct of vigor and the study of positive affect in organizations. In D. Ganster, \& P. L. Perrewe (Eds.), Research in organizational stress and well-being. Greenwich, C. T.: JAI Press.

Shirom, A. (2006). Explaining vigor: On the antecedents and consequences of vigor as a positive affect at work. In C. L. Cooper, \& D. Nelson (Eds.), Organizational behavior: Accentuating the positive at work. Thousand Oaks, C. A.: Sage Publications.

Shirom, A., \& Shraga, O. (2009). On the directionality of vigor-job satisfaction relationships: A longitudinal study. In C. Hartel, W. J. Zerbe, \& N. Ashkanasy (Eds.), Research on emotions in organizations. Bingley, U. K.: Emerald Publishing Company.

Shirom, A., Toker, S., Jacobson, O., \& Balicer, R. (2010). Feeling vigorous and the risks of all-cause mortality, ischemic heart disease and diabetes: A 20-years follow-up of apparently healthy employees. Psychosomatic Medicine, 72, 727-733.

Shraga, O. (2007). Vigor at work: Its construct validity, and its relations with job satisfaction and job characteristics: Triangulating qualitative and quantitative methodologies (Unpublished dissertation, Tel Aviv University).

Shraga, O., \& Shirom, A. (2009). A qualitative investigation into the construct validity of vigor and its antecedents. Human Relations, 62, 271-279.

Smith, M. R., Wefald, A. J., Downey, R. G., \& Gopalan, N. (2008, September). Further support for the factor structure and construct validity of the Shirom-Melamed vigor measure (SMVM). Poster presentation presented at the 3rd Annual International Conference on Occupational Health (ICOH-WPS), Quebec City, Quebec, Canada. 
Spector, P. (2006). Method variance in organizational research: Truth or urban legend? Organizational Research Methods, 9, 221-232. doi:10.1177/1094428105284955

Stajkovic, A. D., Lee, D., \& Nyberg, A. J. (2009). Collective efficacy, group potency, and group performance: Meta-analysis of their relationships, and test of a mediation model. Journal of Applied Psychology, 94, 814-828.

van der Leeden, R., \& Busing, F. M. (1994). First iteration versus IGLS/RIGLS estimates in two-level models: A Monte Carlo study with ML3. Reprint PRM 94-03. Psychometrics and Research Methodology: Leiden, Netherlands.

Vance, R. J. (2006). Employee engagement and commitment: A guide to understanding, measuring and increasing engagement in your organization. Alexandria, V. A.: SHRM Foundation.

Wood, C., Magnello, M. E., \& Jewell, T. (1990). Measuring vitality. Journal of the Royal Society of Medicine, 83, 486-489. 